Saudi Journal of Medicine

Abbreviated Key Title: Saudi J Med ISSN 2518-3389 (Print) |ISSN 2518-3397 (Online)

\title{
Pulmonary Embolism and Internal Carotid Thrombosis in COVID 19 Infections
}

\author{
Achraf Zaimi ${ }^{1 *}$, Nadia Loudiyi ${ }^{1}$, Soukaina Zaimi ${ }^{2}$, Mohamed Malki ${ }^{1}$, Sara Ahchouch ${ }^{1}$, Meriem Boumaaz ${ }^{1}$, Najat \\ Mouine $^{1}$, Ilyasse Asfalou ${ }^{1}$, Aatif Benyass ${ }^{1}$ \\ ${ }^{1}$ Cardiology Center, Military Hospital Mohamed V, Faculty of Medicine and Pharmacy of Rabat, Morocco \\ ${ }^{2}$ Radiology department, Military Hospital Mohamed V, Faculty of Medicine and Pharmacy of Rabat, Morocco
}

DOI: $10.36348 /$ sjm.2021.v06i01.002

| Received: 26.12.2020 | Accepted: 01.01.2021 | Published: 08.01.2021

*Corresponding Author: Achraf Zaimi

\section{Abstract}

Infection with the SARS-Cov-2 virus induces an unusual pre-thrombotic state, of multifactorial origin, responsible for a high incidence of venous thromboembolic events but also of arterial thromboses which have a negative impact on the prognosis of patients. Knowledge of the mechanisms of thrombosis formation has improved significantly since the onset of the pandemic pending appropriate protocols for preventive and curative anticoagulant therapy during COVID 19, emerging from randomized controlled clinical trials. We report the case of a young patient hospitalized with a moderate form of COVID 19 who presented with pulmonary embolism and acute ischemic stroke related to internal carotid thrombosis.

Keywords: COVID 19, pulmonary embolism, ischemic stroke, internal carotid thrombosis.

Copyright () 2021 The Author(s): This is an open-access article distributed under the terms of the Creative Commons Attribution 4.0 International License (CC BY-NC 4.0) which permits unrestricted use, distribution, and reproduction in any medium for non-commercial use provided the original author and source are credited.

\section{INTRODUCTION}

The SARS-Cov-2 virus is a single-stranded RNA virus of the coronaviridae family responsible for the covid 19 pandemic. Respiratory signs are in the foreground with a potential development in acute respiratory distress syndrome, in addition to a trait systemic and hypercoagulable confirmed of this disease causing venous and arterial thrombosis especially in severely affected patients.

\section{OBSERVATION}

This is a 48-year-old patient who has a chronic smooking as a cardiovascular risk factor. No particular history. He reported, a week before his admission, frontal headaches with cough and slight difficulty in breathing in a context of fever and asthenia. On physical examination, the patient presented an altered general condition without dyspnea at rest with a temperature of $39^{\circ}$ and Oxygen saturation at $94 \%$ in ambient air. The PCR test for the SARS Cov 2 virus came back positive and the chest computed tomography showed bilateral and diffuse ground-glass opacities classified as CORADS 5 (Fig. 1), supplemented by a thoracic CT angiography which revealed a marginal thrombosis of the branches of lobar divisions of right pulmonary artery (Fig. 2). In addition to treatment for covid 19, the patient received a curative dose of anticoagulation with low molecular weight heparin (LMWH) (Enoxaparin $60 \mathrm{mg}$ subcutaneous every 12 hours). On the $3 \mathrm{rd}$ day of his hospitalization, he presented a right sensitivomotor deficit related to an acute left sylvian ischemic stroke confirmed by cerebral CT (Fig. 3). As part of the aetiological assessment, supra-aortic trunk ultrasound revealed a thrombosis of the proximal part of the left internal carotid artery floating in the bulb responsible for a complete occlusion (Fig. 4). Aspect confirmed by CT angiography of supraaortic trunk (Fig. 5). 

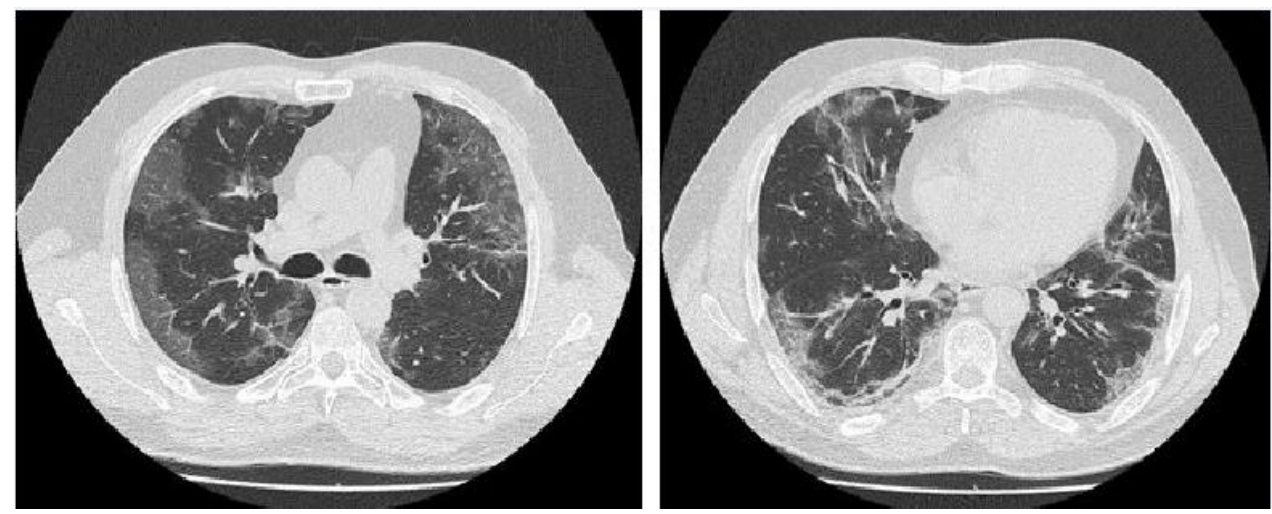

Fig-1: Chest CT: bilateral and diffuse ground-glass opacities classified as CORADS 5

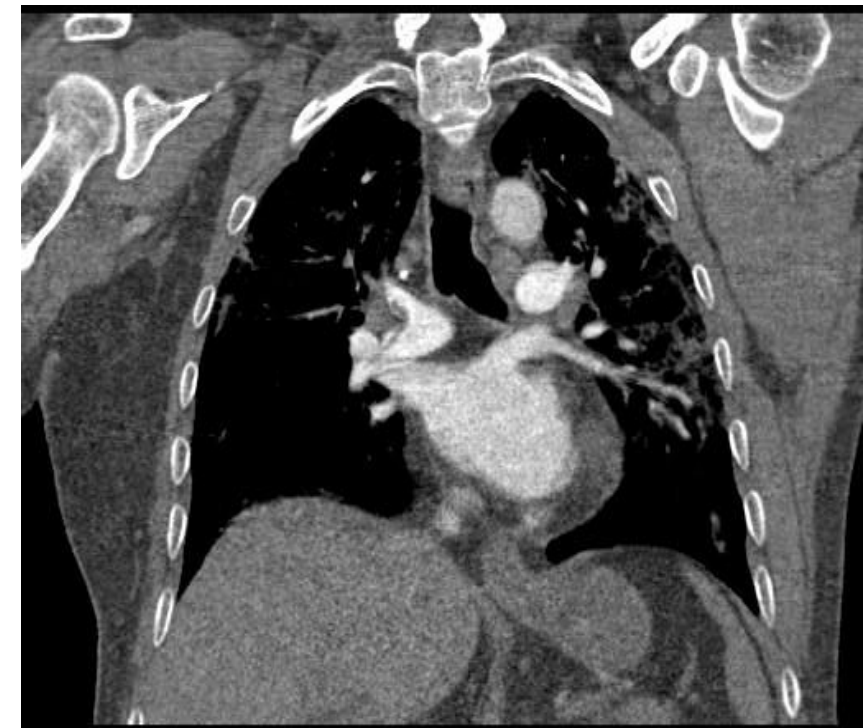

Fig-2: Thoracic CT angiography: marginal thrombosis of the branches of lobar divisions of right pulmonary artery

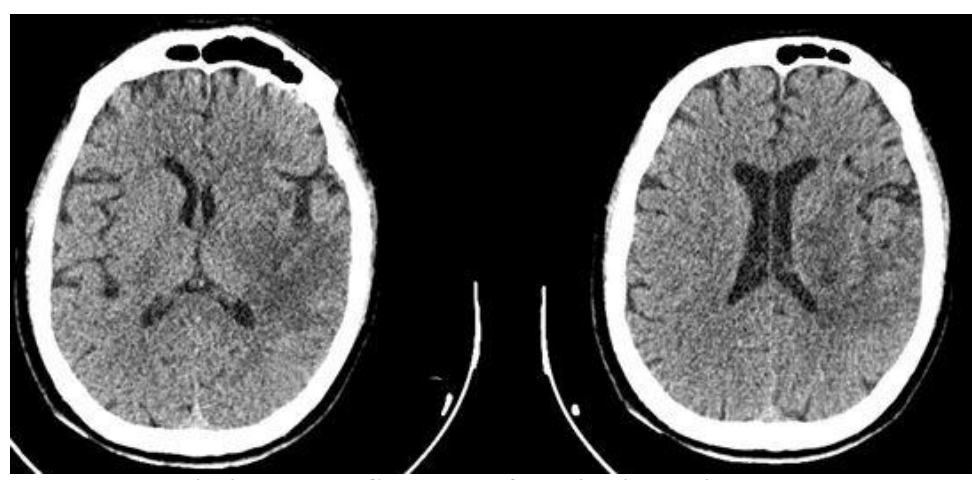

Fig-3: cerebral CT: acute left sylvian ischemic stroke
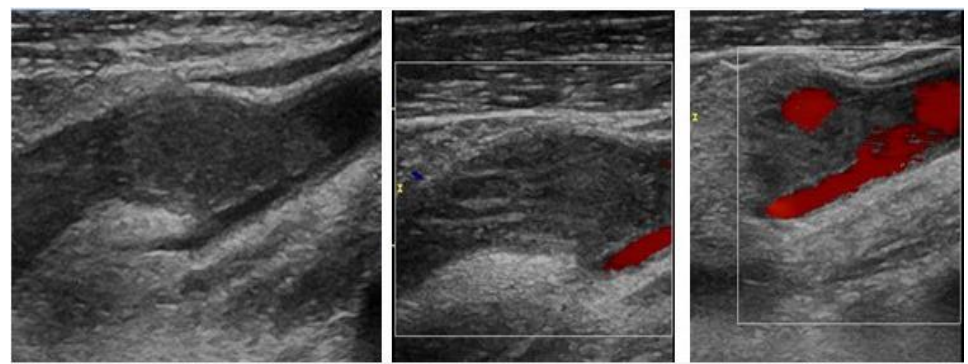

Fig-4: Echodoppler of the supra-aortic trunks (2D and color mode) objectifying a thrombosis of the proximal part of the left internal carotid artery floating at the bulb 


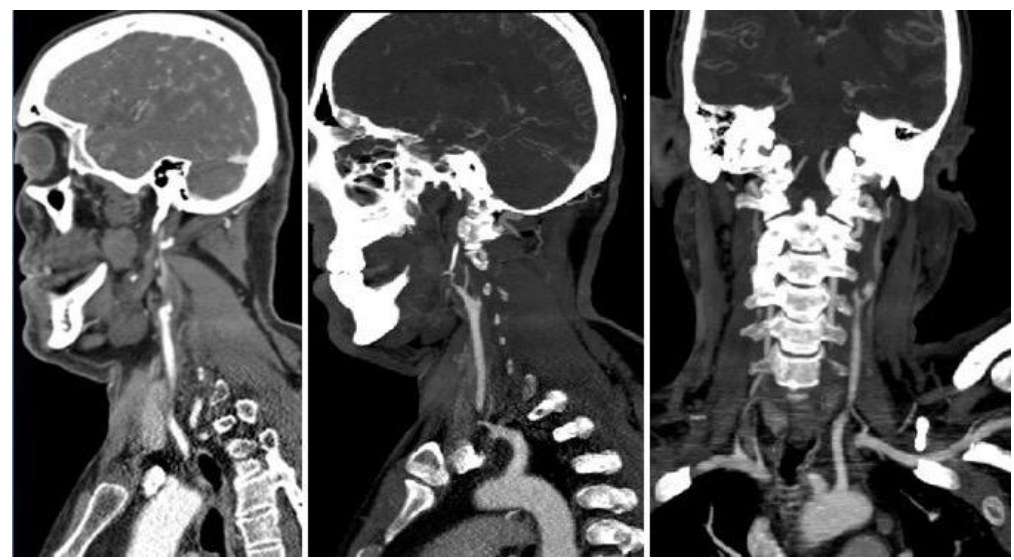

Fig-5: CT angiography of supra-aortic trunks confirming the complete occlusion of the left internal carotid artery

\section{DISCUSSION}

Since the start of the covid 19 pandemic, there has been a strong thrombotic trend among patients with the SARS-Cov-2 virus. These are not only venous thrombosis, but also arterial thrombosis, hemodialysis filters and extracorporeal membrane oxygenation equipment [1].

The increased proportion of venous thromboembolic events (VTE) is explained on the one hand by the presence of risk factors making up the Virchow triad (stasis related to bed rest and obesity, parietal damage by endothelial inflammation and hypercoagulability due to sepsis), and on the other hand, endothelial activation and thrombogenic inflammation (increase in Von Wilebrand factor and factor VIII) due to the virus itself [2].

Indeed, SARS-Cov-2 possesses the ability to penetrate inside host cells via the interaction between its transmembrane glucoprotein and its functional angiotensin converting enzym 2 (ACE 2) receptor expressed in endothelial cells. This results in an intense local inflammation responsible for endotheliitis, leading to the formation of extensive immunothrombosis in the pulmonary vascular bed [3].

Sepsis secondary to covid 19 causes a massive and sustained release of proinflammatory cytokines, also called "cytokine storm", responsible for endothelial dysfunction that causes an imbalance between procoagulant and fibrinolytic factors in favor of thrombosis [4].

The SARS-Cov-2 virus can also be the cause of ischemic stroke. On the one hand, it can cause direct damage to the central nervous system, by hematogenous propagation or retrograde invasion via ACE2 receptor also expressed by nerve cells $[5,6]$. On the other hand, inflammation affects atherosclerotic plaque vulnerability and promotes a thrombogenic environmenthas [7]. The fact that all patients presented with involvement at the carotid bifurcation may be due to its pre-existing propensity for atherosclerosis and turbulent flow; the latter can damage the endothelium and lead to platelet aggregation.

Among the recently advanced mechanisms we find the notion of cerebral vasculitis. In fact, antiphospholipid antibodies have been shown to be positive in patients severely infected with SARS-Cov-2 and presenting with multiple ischemic stroke $[8,9]$.

Thromboprophylaxis with LMWH, unfractionated heparins or fondaparinux should be routine in all patients hospitalized for covid 19, as several studies have found a decrease in mortality in patients who received anticoagulation during hospitalization for covid19 in comparison with those who did not receive it $[10,11]$. Some authors report the occurrence of VTE in patients hospitalized for covid 19 despite preventive anticoagulation. Thus, it seems that VTE associated with covid 19 have specific risk factors such as male sex, the time between the onset of symptoms and hospitalization, the absence of preventive anticoagulation and a marked inflammatory syndrome $[12,13]$.

\section{CONCLUSION}

Infection with the SARS cov2 virus or covid 19 diseases is an aggressive endothelial disease that provides a unifying pathophysiological picture and also a framework for a rational treatment strategy, at a time when we have a modest evidence base to guide our therapeutic attempts and face this pandemic.

\section{RÉFÉRENCES}

1. Helms, J., Tacquard, C., Severac, F., LeonardLorant, I., Ohana, M., Delabranche, X., ... \& Meziani, F. (2020). High risk of thrombosis in patients with severe SARS-CoV-2 infection: a multicenter prospective cohort study. Intensive care medicine, 1-10.

2. Ackermann, M., Verleden, S. E., Kuehnel, M., Haverich, A., Welte, T., Laenger, F., ... \& Jonigk, D. (2020). Pulmonary vascular endothelialitis, thrombosis, and angiogenesis in Covid-19. New England Journal of Medicine. 
3. McGonagle, D., O'Donnell, J. S., Sharif, K., Emery, P., \& Bridgewood, C. (2020). Immune mechanisms of pulmonary intravascular coagulopathy in COVID-19 pneumonia. The Lancet Rheumatology.

4. Libby, P., \& Lüscher, T. (2020). COVID-19 is, in the end, an endothelial disease. European heart journal, 41(32), 3038-3044.

5. Gane, S. B., Kelly, C., \& Hopkins, C. (2020). Isolated sudden onset anosmia in COVID-19 infection. A novel syndrome. Rhinology, 10.

6. Politi, L. S., Salsano, E., \& Grimaldi, M. (2020). Magnetic resonance imaging alteration of the brain in a patient with coronavirus disease 2019 (covid19) and anosmia. JAMA Neurology.

7. Hartmann, P., Schober, A., \& Weber, C. (2015). Chemokines and microRNAs in atherosclerosis. Cellular and Molecular Life Sciences, 72(17), 3253-3266.

8. Beyrouti, R., Adams, M. E., Benjamin, L., Cohen, H., Farmer, S. F., Goh, Y. Y., ... \& Werring, D. J. (2020). Characteristics of ischaemic stroke associated with COVID-19. Journal of Neurology, Neurosurgery \& Psychiatry.

9. Bowles, L., Platton, S., Yartey, N., Dave, M., Lee, K., Hart, D. P., ... \& MacCallum, P. (2020). Lupus anticoagulant and abnormal coagulation tests in patients with Covid-19. New England Journal of Medicine.

10. Tang, N., Li, D., Wang, X., \& Sun, Z. (2020). Abnormal coagulation parameters are associated with poor prognosis in patients with novel coronavirus pneumonia. Journal of thrombosis and haemostasis, 18(4), 844-847.

11. Paranjpe, I., Fuster, V., Lala, A., Russak, A. J., Glicksberg, B. S., Levin, M. A., ... \& Nadkarni, G. N. (2020). Association of treatment dose anticoagulation with in-hospital survival among hospitalized patients with COVID-19. Journal of the American College of Cardiology, 76(1), 122124.

12. Fauvel, C., Weizman, O., Trimaille, A., Mika, D., Pommier, T., Pace, N., ... \& Critical Covid-19 France Investigators. (2020). Pulmonary embolism in COVID-19 patients: a French multicentre cohort study. European heart journal, 41(32), 3058-3068.

13. Trimaille, A., Curtiaud, A., Marchandot, B., Matsushita, K., Sato, C., Leonard-Lorant, I., ... \& Morel, O. (2020). Venous thromboembolism in non-critically ill patients with COVID-19 infection. Thrombosis research, 193, 166-169. 